\title{
Effect of tetracycline HCL (periodontal plus AB) on Aggregatibacter actinomycetemcomitans levels in chronic periodontitis
}

Sneha Kataria, Kabbur Thippanna Chandrashekar*, Rohit Mishra, Vandana Tripathi, Ankit Galav and Upasana Sthapak

*Corresponding: ktcshekars@gmail.com

Department of Periodontics, Hitkarini Dental College and Hospital, Jabalpur, Madhya Pradesh, India.

\begin{abstract}
Objectives: To evaluate the efficacy of tetracycline fiber (used as local drug delivery) along with scaling and root planing for the treatment of chronic periodontitis, and compare the results with those ensuing after scaling and root planing alone.

Material and methods: A total of 50 patients were selected for the study. The treatment sites were divided into two groups by a split mouth technique. In each patient, periodontal pockets were treated with scaling and root planing alone (control site), or treated by scaling and root planing followed by placement of tetracycline fiber (test site), with the aim of evaluating Aggregatibacter actinomycetemcomitans in chronic periodontitis. Gingival index, probing depth, clinical attachment levels and quantitative and qualitative analysis of Aggregatibacter actinomycetemcomitans was carried out at baseline and 14 day after treatment. The significance of any difference between test and control sites was tested using independent sample Student's $t$ tests.

Results: After fourteen days, there was a statistically significant improvement in all variables including gingival index score, pocket probing depth, clinical attachment levels and reduction in colony counts of Aggregatibacter actinomycetemcomitans. However, inter group comparison showed statistically significant improvement only in the colony count of Aggregatibacter actinomycetemcomitans in the test group.

Conclusion: When compared with scaling and root planing alone, tetracycline fiber therapy along with scaling and root planing improves periodontal parameters and significantly reduces bacterial colony count in treatment of chronic periodontitis.
\end{abstract}

Keywords: Collagen, periodontitis, tetracycline fibers, Aggregatibacter actinomycetemcomitans

\section{Introduction}

Chronic Periodontitis is defined as an infectious disease resulting in inflammation within the supporting tissues of the teeth, progressive attachment and bone loss and is characterized by pocket formation and/or recession of the gingiva and mainly prevalent in adults, but can occur at any age. Even though it is a multifactorial disease, the primary etiology is the presence of plaque and calculus. Progression of attachment loss usually occurs slowly, but periods of rapid progression can occur. It is known to be associated with a variable microbial pattern [1]. The most common periodontal microbiota associated with chronic periodontitis includes aerobic, anaerobic, gram positive and gram negative bacterial flora. Amongst the anaerobic bacteria, the most commonly implicated bacteria include Aggregatibacter actinomycetemcomitans, Porphyromonas gingivalis, Tannerella forsythia, Prevotella intermedia and Campylobacter rectus, as 
Chandrashekar et al. Oral Biology and Dentistry 2015,

they are found in increased quantity in active sites and their elimination by therapy is associated with improved clinical features [2]. Among these bacteriae also, Aggregatibacter actinomycetemcomitans is found in most diseased sites and may compose as much as $90 \%$ of the total cultivable bacteria [3]. It is thus considered as the most important pathogen for periodontitis and refractory periodontitis.

The conventional periodontal therapy aims at complete elimination of the primary etiologic factor, plaque and other predisposing factors such as calculus, over hanging restorations, faulty prosthesis etc [4]. Scaling and Root Planning (SRP) forms a vital part of the first phase of periodontal therapy, as it leads to significant improvement in the clinical parameters [5]. However, different patients respond differently to mechanical therapy and the period over which the improved results can be maintained also varies in different individuals. The microbiological profile of an individual plays an important role in the outcome of mechanical therapy [2].

Since the mechanical therapy fails to eliminate bacteria which penetrate the connective tissue, the use of antibiotics as adjuncts to SRP has been advocated. In a systematic review, Haffajee et al., (2003) concluded that the use of systemic antibiotics leads to improved clinical parameters as compared to treatment with scaling alone [6]. However, the disadvantages like development of resistant strains, incidence of super infections and systemic side effects limit their wide spread use. Also, systemically administered antibiotics fail to penetrate the periodontal biofilm which requires an antibiotic strength of about 500 times greater than the usual therapeutic dose [7].

Local application of antibiotic or antiseptic in direct contact with the root surface can reduce or eliminate pathogenic organisms that could not be eradicated mechanically [5]. They also offer the advantages of high concentrations at the target sites with reduced systemic dosing, fewer applications, and high patient acceptability. The local delivery system maintains effective intra-pocket levels of antibacterial agents for extended period of time, so that they can alter subgingival flora and influence the healing of attachment apparatus [4].

Amongst the various antibiotics used for local application, tetracycline is favoured due to its better resorption, protein binding capability, diffusion into tissue structures, and prolonged duration of action. These unique drugs constitute the only class of antimicrobials tested to date that achieve higher concentrations in gingival fluid than in blood. Tetracyclines also help to increase reattachment or regeneration by enhancing fibroblast activity and conditioning of root surfaces by inhibiting collagenase activity [6].

Since, Aggregatibacter actinomycetemcomitans is one of the most pathogenic bacteria responsible for all forms of periodontal diseases, the present clinical study, a split-mouth randomized control trial, was aimed to compare the effect of resorbable tetracycline fibres (Periodontal Plus $\mathrm{AB}^{\circledR}$ ) as an adjunct to scaling and root planing on clinical parameters and the levels of Aggregatibacter actinomycetemcomitans in adults diagnosed with chronic periodontitis.

\section{Materials and methods Source of data}

This clinical study was conducted in the Department of Periodontics, Hitkarini Dental College and Hospital, Jabalpur, Madhya Pradesh, India. Fifty patients were selected including both males and females in the age group of 30-55 years diagnosed with chronic periodontitis.

\section{Selection of patients}

Patients diagnosed with chronic periodontitis with probing depth of $\geq 5 \mathrm{~mm}$ and radiographic evidence of bone loss at atleast two non-adjacent sites were selected. The patients who were able to maintain good oral hygiene and had not received any antibiotics in the past six months were included in the study. None of the patients had received any periodontal treatment before the baseline examination. Patients were excluded if they had any systemic disease such as diabetes, if they were allergic to tetracycline fibres, pregnant or lactating or were using any medicated mouthrinse on a routine basis.

The study design was approved by the ethical committee of Hitkarini Dental College \& Hospital, Jabalpur, Madhya Pradesh, India.

\section{Clinical trial design}

A written informed consent form explaining the nature of the study and procedure for local drug delivery was obtained from all the patients. In each patient, the treatment sites were divided into two groups randomly by the split-mouth technique: Test Group A (SRP+Periodontal Plus AB) and Control Group B (SRP alone). All clinical parameters and plaque samples were collected at baseline (zero days) and $14^{\text {th }}$ day respectively.

\section{Tetracycline fibers (Periodontal Plus AB ${ }^{m}$ (Advanced Biotech Products, Chennai, India))}

Figure 1 the product contains $25 \mathrm{mg}$ pure fibrilar collagen, containing approximately $2 \mathrm{mg}$ of evenly impregnated tetracycline HCL, sterilized by gamma radiation with shelf life of 2 years. It releases tetracycline and it gets dissolve in the period of 8-12 days. Periodontal Plus AB Fibers are available in strips containing four individually packed and separable sterile product packs.

\section{Clinical measurements}

Gingival index [9], pocket probing depth and clinical attachment level were recorded at baseline and repeated on $14^{\text {th }}$ day after the treatment.

\section{Probing pocket depth}

The pocket depth was measured using a Hu Freidy UNC 15 probe from fixed reference point (FRP) on the stent to the base of the pocket (BOP) (Figure 2) and from the fixed reference point to the free gingival margin (GM). Probing pocket depth was obtained by subtracting distance of the Fixed Reference Point to Gingival Margin from Fixed Reference Point to Base of Pocket. 


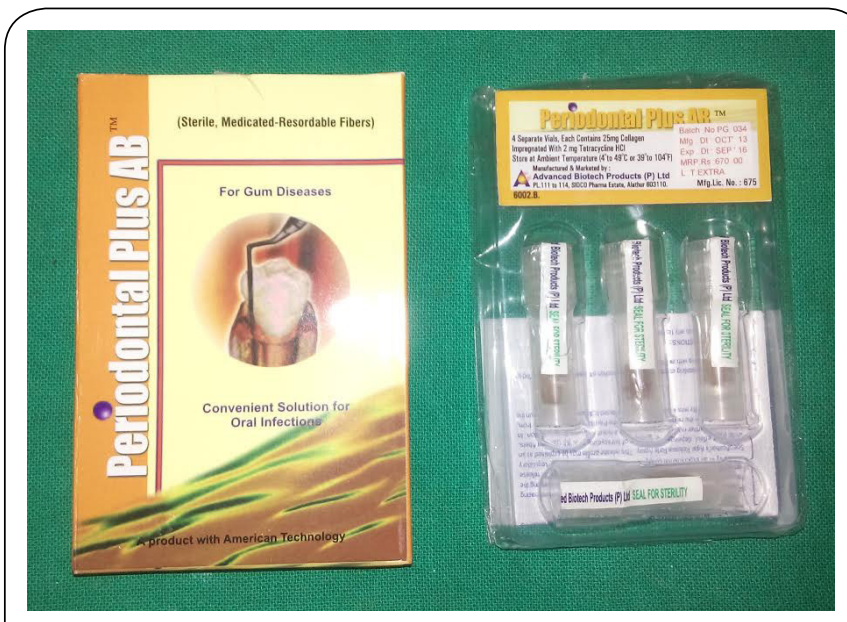

Figure 1. Periodontal Plus $\mathrm{AB}^{\mathrm{TM}}$ (Tetracycline fibers).

The measurement was recorded to the nearest millimetre and the recording was entered into the customized performa made for the study for each patient. The customized occlusal stents were stored on the prepared study casts to minimize distortion and to record on the $14^{\text {th }}$ day.

\section{Clinical attachment level}

The customized occlusal stent was placed on the selected teeth and the probe was gently inserted along the groove on the stent. The distance from the fixed reference point on the stent to the base of the pocket and distance from fixed reference point to the Cemento-Enamel Junction (CEJ) were recorded. Clinical attachment level was obtained by subtracting the distance of fixed reference point to cemento enamel junction from fixed reference point to base of pocket.

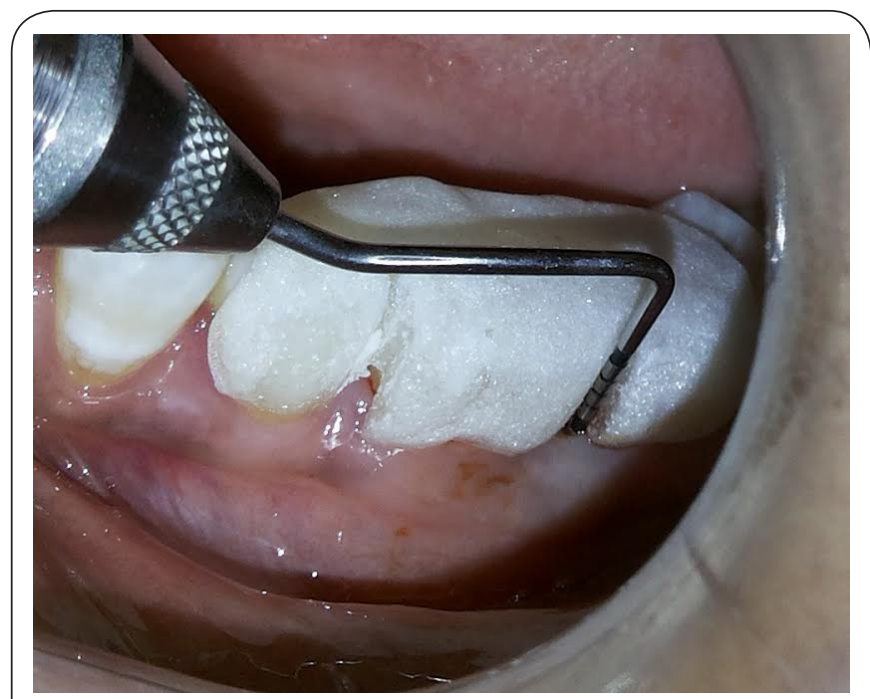

Figure 2. Measurement of probing depth using UNC 15 periodontal probe and acrylic stent.
After the clinical parameters were recorded at baseline, the tetracycline fibres (Periodontal Plus AB) were placed at the respective site (Figure 3 ) and the treated areas were given periodontal pack to isolate the area and to restrict the effect of the tetracycline fibres to particular sites for at least a week. The patient was informed to report to the clinic in case of any irritation or dysfunction. After the placement of Periodontal Plus AB drug, patients were instructed not to floss and probe the area with tongue, finger or toothpick and report immediately, if the material or pack is dislodged before the scheduled recall visit or if any pain, swelling or irritation occurred.

\section{Collection of subgingival plaque samples}

Sub gingival plaque samples were collected at baseline and 14 days after the treatment. Samples were collected with complete aseptic precautions. The tooth was first isolated with cotton rolls, gently dried by air syringe and the supragingival plaque was removed. Care was taken not to disturb the subgingival plaque. Two sterile paper points were inserted in the gingival sulcus for $10 \mathrm{sec}$. The paper points which were contaminated by saliva or blood were discarded. The paper points were immediately placed in thioglycolate transport medium and transported to the laboratory for microbiological evaluation (Figures 4 and $\mathbf{5}$ ).

\section{Microbiological lab investigations}

The samples were processed within 24 hours. Each sample was first inoculated on Wilkins Chalgren Agar Medium [11] (Figure 6). The plates were incubated in vacuum dessicator at $37^{\circ} \mathrm{C}$ under anaerobic conditions. After seven days, Aggregatibacter actinomycetemcomitans colonies were seen as star shaped (Figure 7). Bacteria from the pure culture were subjected to various tests. Identification was confirmed based on cell morphology (rod shaped), Gram stain reaction (Gram negative), biochemical and enzymatic tests including Indole test (negative), Carbohydrate fermentation test (positive for glucose, lactose and sucrose), Gas production test $\left(\mathrm{H}_{2} \mathrm{~s}\right)$ (negative), Catalase test (positive).

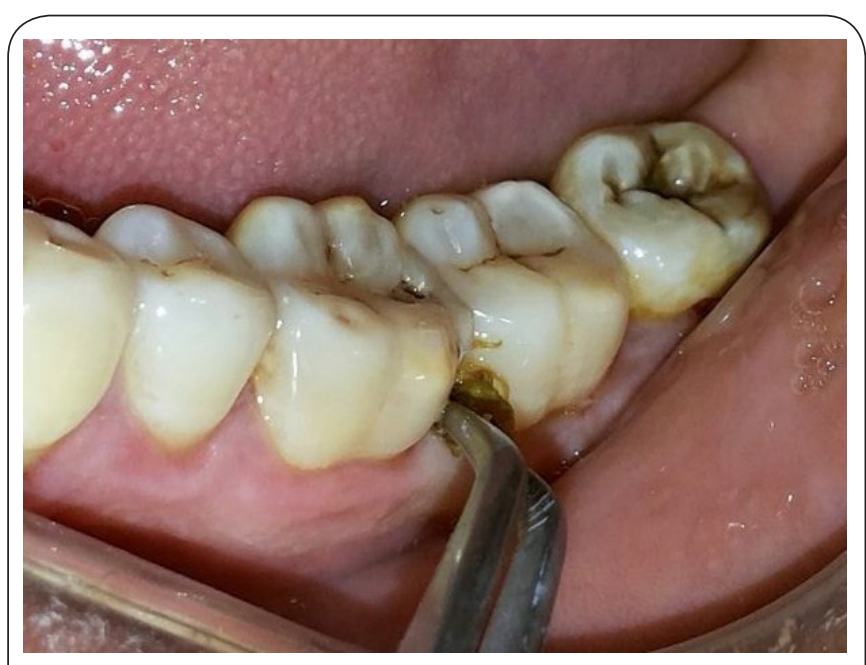

Figure 3. Placement of tetracycline fibres in periodontal pocket. 


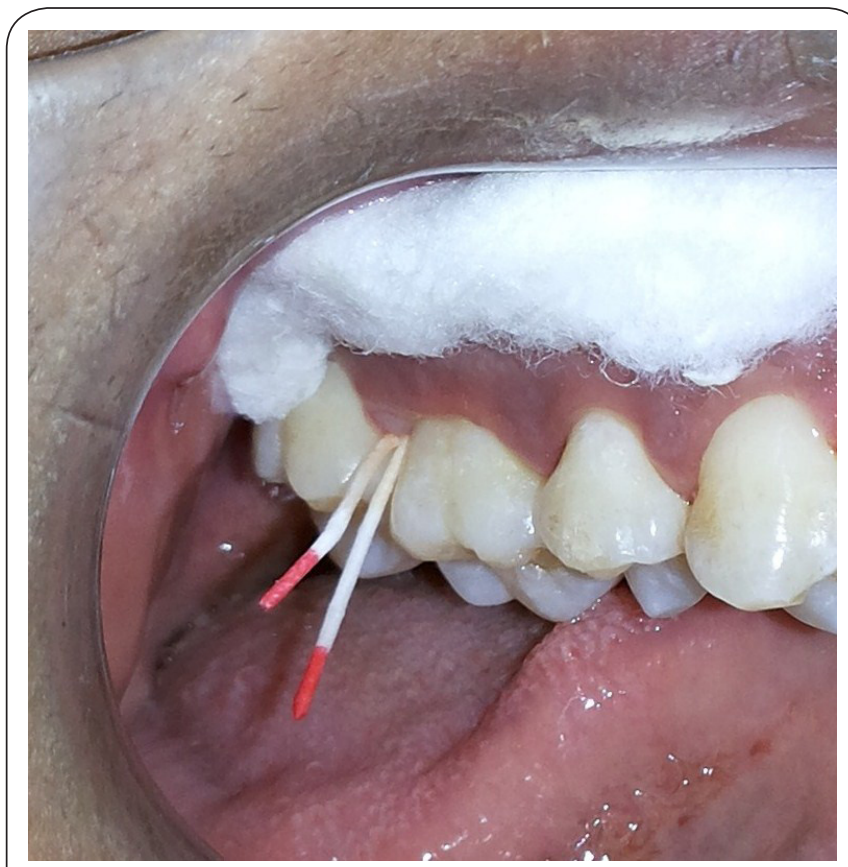

Figure 4. Collecting of subgingival plaque sample using paper points.

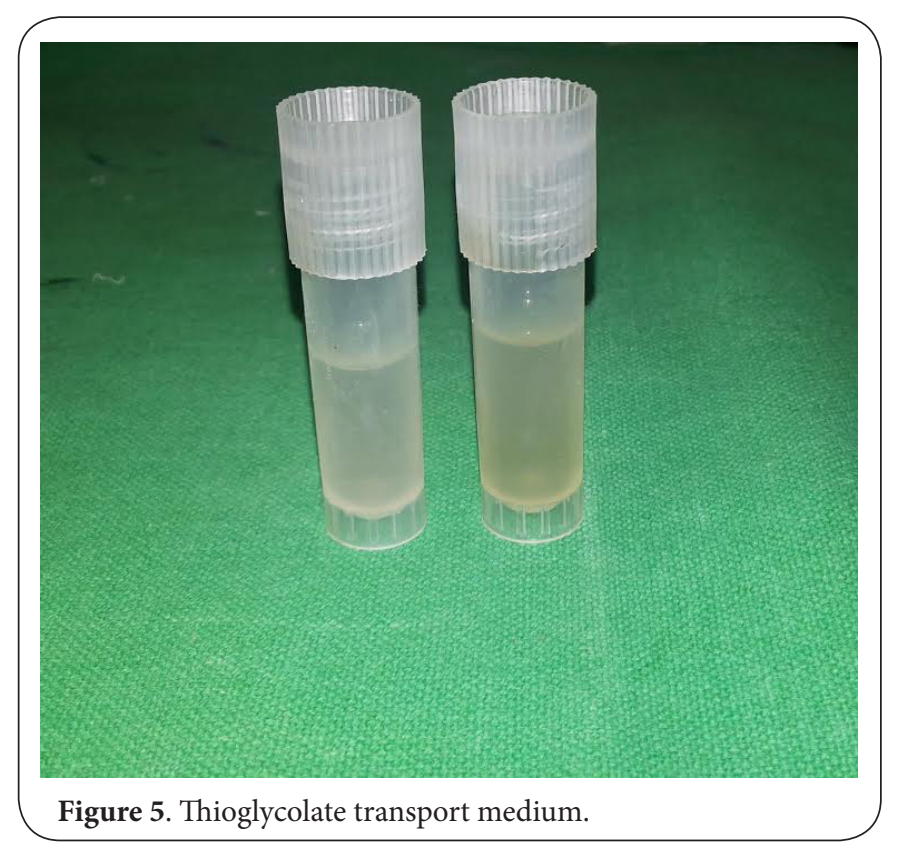

\section{Data analysis}

Independent ' $\mathrm{t}$ ' and Paired ' $\mathrm{t}$ ' test, were employed in the present study for analysis of data using SPSS for Windows (Statistical Presentation System Software, 1999, SPSS Inc, New York) version 10.0.

\section{Results}

The gingival index, pocket probing depth, clinical attachment

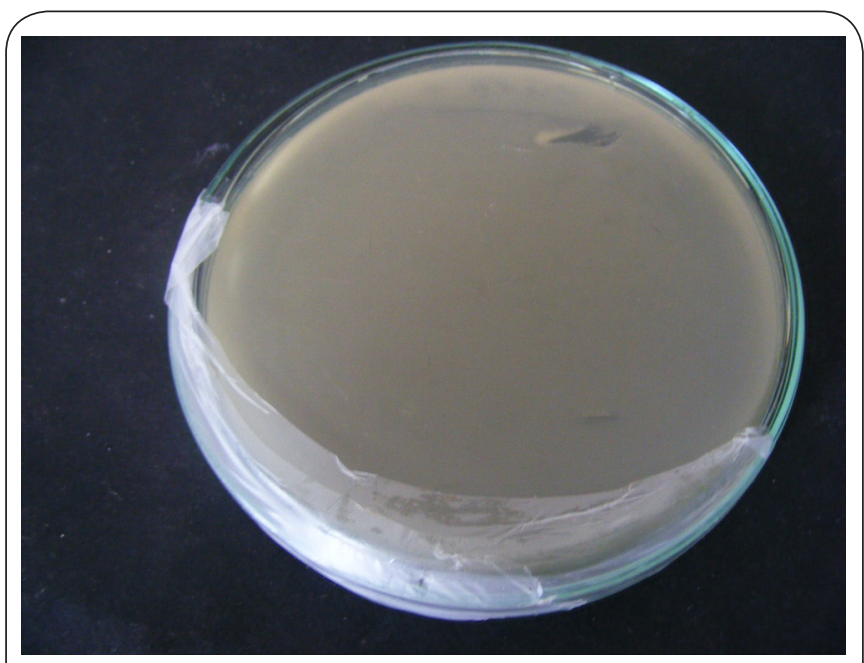

Figure 6. Wilkins chalgren agar medium.

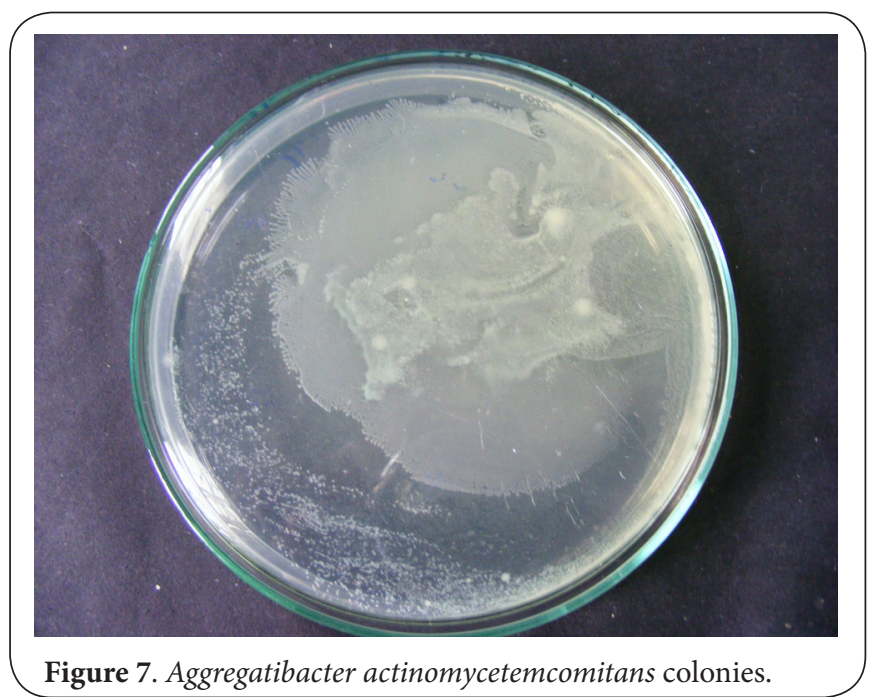

level and colony forming units for one hundred sites in fifty patients were assessed.

\section{Gingival index}

Comparative analysis of test and control group at baseline revealed mean scores of $1.17 \pm 0.568$ and $1.35 \pm 0.489$ respectively with a ' $t$ ' value of $t=1.0435$ indicating no significant difference between the two groups $(\mathrm{p}>0.05)$. At $14^{\text {th }}$ day mean of test and control group were $0.74 \pm 0.681$ and $0.56 \pm 0.399$ with a ' $t$ ' value is $\mathrm{t}=0.9917$ indicating no significant difference between two groups $(p>0.05)$. However, statistically significant reduction was seen in both the groups from baselline ( $\mathrm{p}<0.05)$ (Table 1, Graph 1).

\section{Probing pocket depth}

Comparative analysis of test and control group at baseline revealed mean scores of $5.80 \pm 1.105$ and $6.10 \pm 1.252$ respectively with a ' $t$ ' value of $\mathrm{t}=0.8033$ indicating no significant difference between 
the two groups ( $\mathrm{p}>0.05)$. At $14^{\text {th }}$ day, mean value of test group is $3.90 \pm 1.119$ and control group is $4.25 \pm 1.251$ resulting in a ' $\mathrm{t}$ ' value of $\mathrm{t}=0.9324$ indicating no significant difference between the two groups ( $>0.05$ ) (Table 2, Graph 2).

\section{Clinical attachment level}

The mean gain in clinical attachment level when compared from baseline to $14^{\text {th }}$ day in test and control groups was $13.15 \pm 1.631$ to $14.45 \pm 2.481$ and $11.80 \pm 1.473(10.10 \%)$ to $12.95 \pm 2.523(10.60 \%)$ respectively indicating no significant difference between the two groups (Table 3, Graph 3).

\section{Colony forming units}

The mean colony forming units $/ \mathrm{ml}$ in test group at baseline was $245.50 \pm 63.071$ (Figure 8) which reduced to $18.57 \pm 9.748$ (91.1\%) on $14^{\text {th }}$ day (Figure 9) and mean colony forming units $/ \mathrm{ml}$ in control group at baseline was $289.45 \pm 55.618$ (Figure 10) which reduced to $136.00 \pm 26.983(51 \%)$ on the $14^{\text {th }}$ day (Figure 11). On comparison between the two groups, test group revealed $91.1 \%$ reduction in colonies of Aggregatibacter actinomycetemcomitans, compared to $51.0 \%$ of control group (Table 4, Graph 4).

\section{Discussion}

The present clinical study was conducted to evaluate efficacy of tetracycline fibres as an adjunct to scaling and root planing

Table 1. Mean gingival index before and after treatment.

\begin{tabular}{|c|c|c|c|c|c|}
\hline \multirow[t]{2}{*}{$\begin{array}{l}\text { Plaque } \\
\text { Index }\end{array}$} & \multicolumn{2}{|c|}{$\begin{array}{c}\text { Experimental sites } \\
\text { (Group A) }\end{array}$} & \multicolumn{2}{|c|}{$\begin{array}{l}\text { Control sites } \\
\text { (Group B) }\end{array}$} & \multirow[t]{2}{*}{$P$ value } \\
\hline & Mean \pm SD & $\begin{array}{l}\text { \% Change } \\
\text { from } \\
\text { baseline }\end{array}$ & $\operatorname{Mean} \pm S D$ & $\begin{array}{l}\text { \% Change } \\
\text { from } \\
\text { baseline }\end{array}$ & \\
\hline Baseline & $1.17 \pm 0.568$ & -- & $1.35 \pm 0.489$ & -- & $\begin{array}{l}t=1.0435 \\
p>0.05^{\star}\end{array}$ \\
\hline $14^{\text {th }}$ day & $0.74 \pm 0.681$ & $62.50 \%$ & $0.56 \pm 0.399$ & $53.10 \%$ & $\begin{array}{l}t=0.9917 \\
p>0.05^{\star}\end{array}$ \\
\hline $\begin{array}{l}\text { Significance } \\
0 \text { day } \mathrm{v} / \mathrm{s} \\
15 \text { days }\end{array}$ & \multicolumn{2}{|c|}{$\mathrm{t}=3.270 ; \mathrm{p}<0.05$} & \multicolumn{2}{|c|}{$\mathrm{t}=6.786 ; \mathrm{p}<0.05$} & -- \\
\hline
\end{tabular}

* Significant

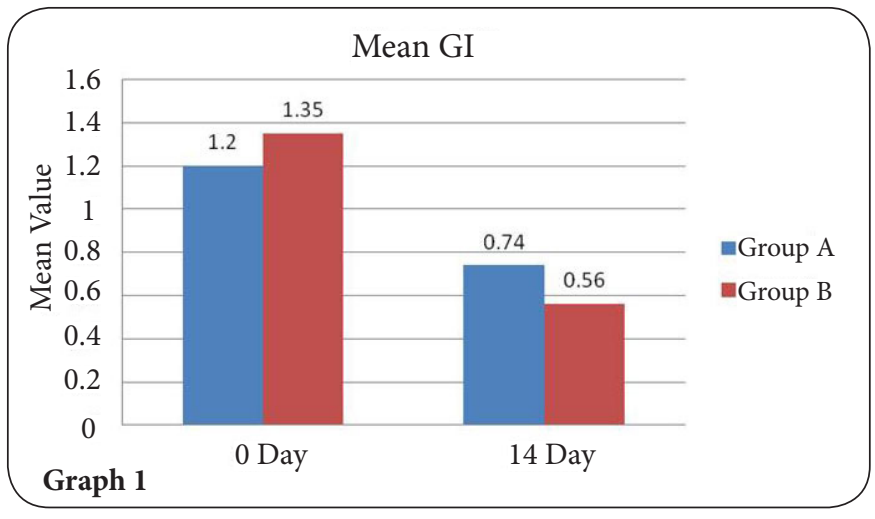

Table 2. Mean probing depth before and after treatment.

\begin{tabular}{|c|c|c|c|c|c|}
\hline \multirow[t]{2}{*}{ Plaque index } & \multicolumn{2}{|c|}{$\begin{array}{c}\text { Experimental sites } \\
\text { (Group A) }\end{array}$} & \multicolumn{2}{|c|}{$\begin{array}{l}\text { Control sites } \\
\text { (Group B) }\end{array}$} & \multirow[t]{2}{*}{ P value } \\
\hline & Mean \pm SD & $\begin{array}{l}\% \text { Change } \\
\text { from } \\
\text { baseline }\end{array}$ & Mean \pm SD & $\begin{array}{l}\text { \% Change } \\
\text { from } \\
\text { baseline }\end{array}$ & \\
\hline Baseline & $\begin{array}{l}5.8 \pm 1.105 \\
(\mathrm{~N}=20)\end{array}$ & -- & $\begin{array}{l}6.1 \pm 1.252 \\
(\mathrm{~N}=20)\end{array}$ & -- & $\begin{array}{l}t=0.8033 \\
p>0.05^{*}\end{array}$ \\
\hline 14th day & $\begin{array}{l}3.9 \pm 1.119 \\
(\mathrm{~N}=20)\end{array}$ & $31.00 \%$ & $\begin{array}{l}4.25 \pm 1.251 \\
(\mathrm{~N}=20)\end{array}$ & $33.70 \%$ & $\begin{array}{l}t=0.9324 \\
p>0.05^{*}\end{array}$ \\
\hline $\begin{array}{l}\text { Significance } \\
0 \text { day v/s } \\
14 \text { days }\end{array}$ & \multicolumn{2}{|c|}{$\mathrm{t}=27.606 ; \mathrm{p}<0.0001$} & \multicolumn{2}{|c|}{$\mathrm{t}=14.091 ; \mathrm{p}<0.0001$} & -- \\
\hline
\end{tabular}

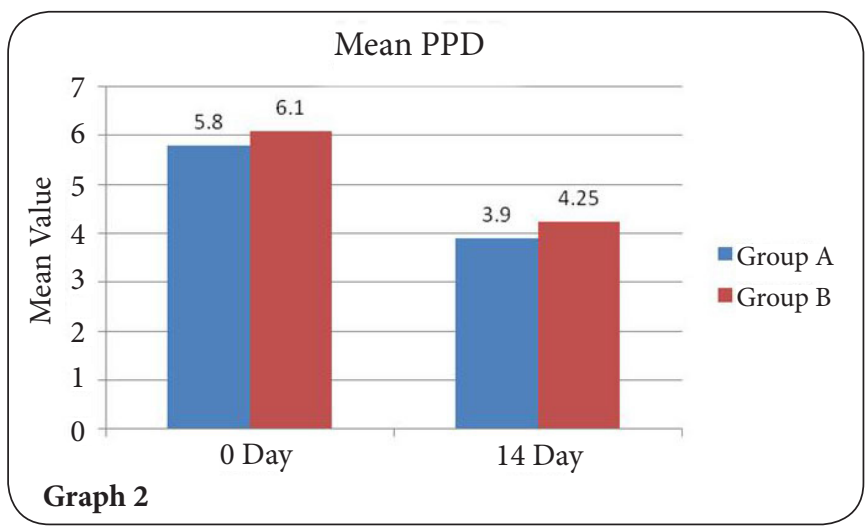

Table 3. Mean relative attachment level before and after treatment.

\begin{tabular}{|c|c|c|c|c|c|}
\hline \multirow[t]{2}{*}{$\begin{array}{l}\text { Plaque } \\
\text { Index }\end{array}$} & \multicolumn{2}{|c|}{$\begin{array}{c}\text { Experimental sites } \\
\text { (Group A) }\end{array}$} & \multicolumn{2}{|c|}{$\begin{array}{c}\text { Control sites } \\
\text { (Group B) }\end{array}$} & \multirow[t]{2}{*}{$P$ value } \\
\hline & Mean \pm SD & $\begin{array}{l}\% \text { Change } \\
\text { from } \\
\text { baseline }\end{array}$ & Mean \pm SD & $\begin{array}{l}\text { \% Change } \\
\text { from } \\
\text { baseline }\end{array}$ & \\
\hline Baseline & $\begin{array}{l}13.15 \pm 1.631 \\
(\mathrm{~N}=20)\end{array}$ & -- & $\begin{array}{l}14.45 \pm 2.481 \\
(\mathrm{~N}=20)\end{array}$ & -- & $\begin{array}{l}\mathrm{t}=1.9581 \\
\mathrm{p}>0.05^{*}\end{array}$ \\
\hline $14^{\text {th }}$ day & $\begin{array}{l}11.8 \pm 1.473 \\
(\mathrm{~N}=20)\end{array}$ & $10.60 \%$ & $\begin{array}{l}12.95 \pm 2.523 \\
(\mathrm{~N}=20)\end{array}$ & $10.10 \%$ & $\begin{array}{l}t=1.7605 \\
p>0.05^{\star}\end{array}$ \\
\hline $\begin{array}{l}\text { Significance } \\
0 \text { day v/s } \\
14 \text { days }\end{array}$ & \multicolumn{2}{|c|}{$t=27.606 ; p<0.0001$} & \multicolumn{2}{|c|}{$\mathrm{t}=14.091 ; \mathrm{p}<0.0001$} & \\
\hline
\end{tabular}

* Significant

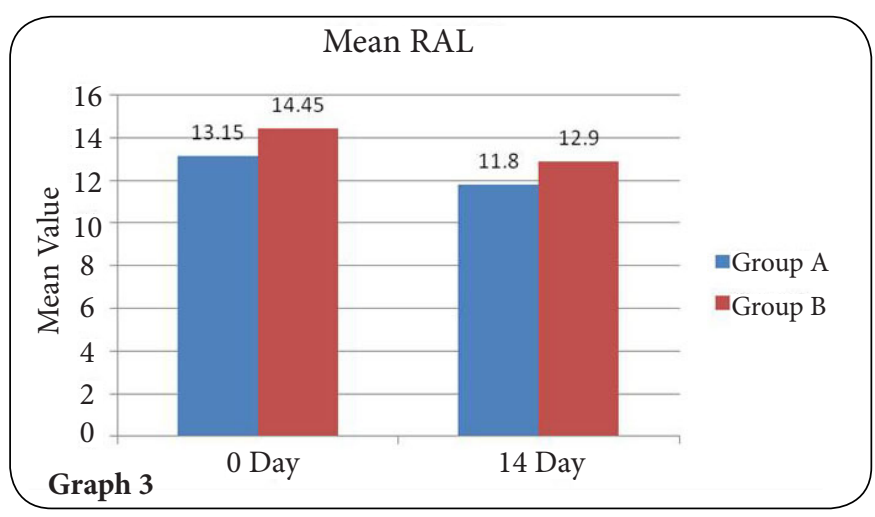




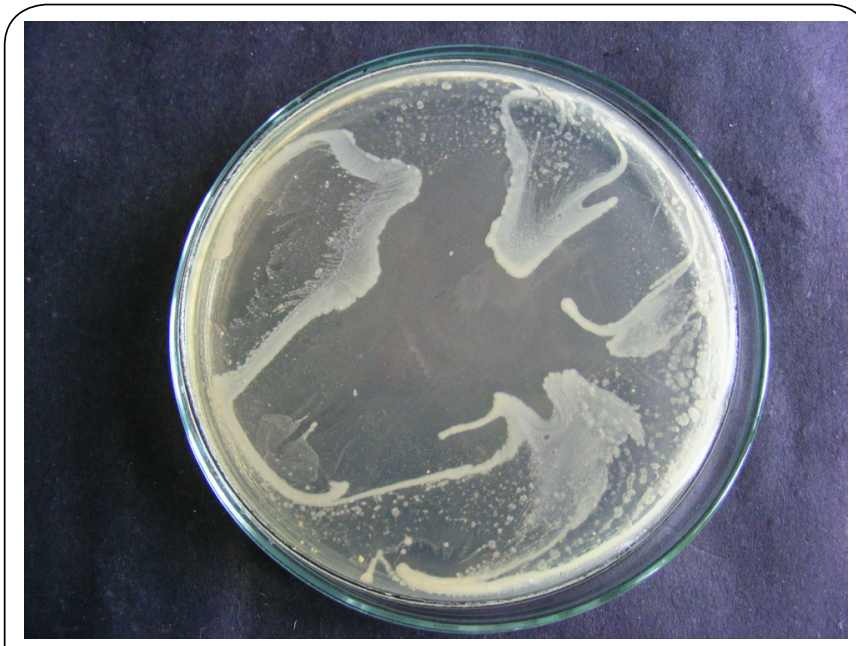

Figure 8. Growth of Aggregatibacter actinomycetemcomitans seen in baseline sample from test group.

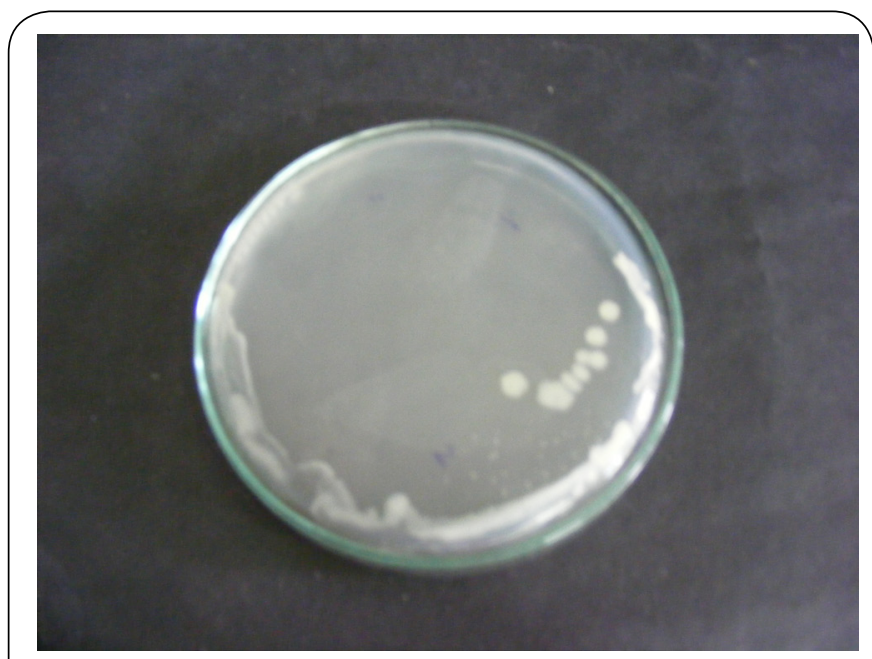

Figure 9. Growth of Aggregatibacter actinomycetemcomitans seen in $14^{\text {th }}$ day sample from test group.

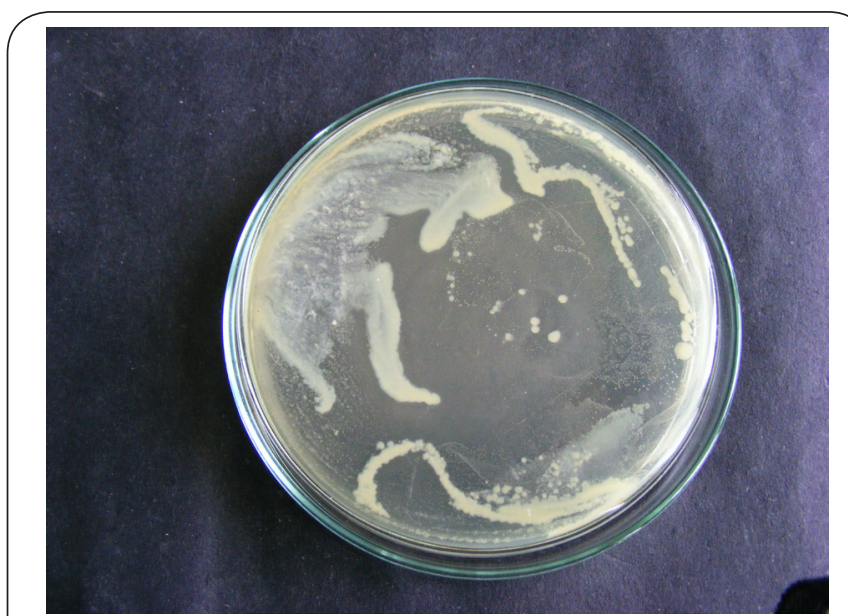

Figure 10. Growth of Aggregatibacter actinomycetemcomitans seen in baseline sample from control group.

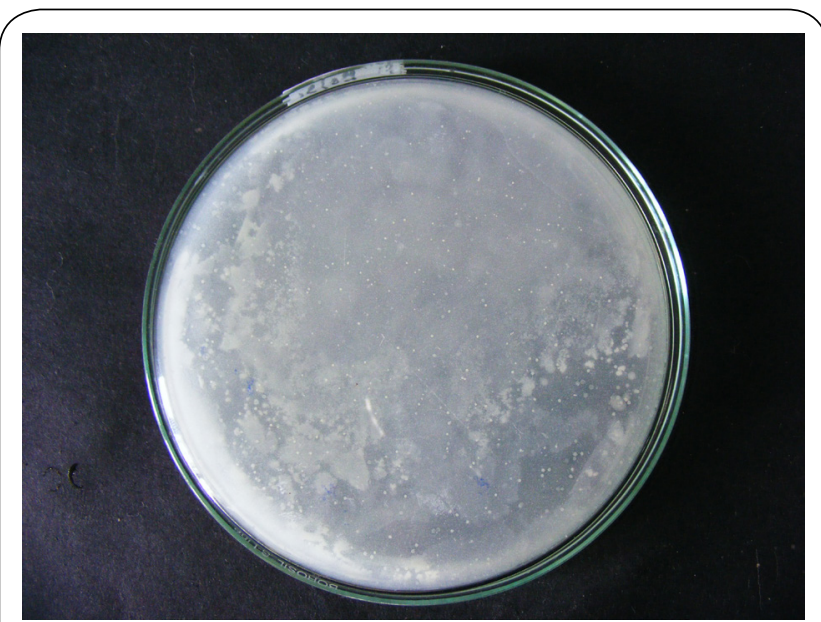

Figure 11. Growth of Aggregatibacter actinomycetemcomitans seen in $14^{\text {th }}$ day sample from control group.

for the treatment of chronic periodontitis and its effect on the subgingival levels of Aggregatibacter actinomycetemcomitans. Fifty patients were enrolled in the study and were treated with either combination of SRP and tetracycline fibres or SRP alone. Statistical analysis of the results showed that there was significant

Table 4. Mean CFU before and after treatment.

\begin{tabular}{|c|c|c|c|c|c|}
\hline \multirow[t]{2}{*}{$\begin{array}{l}\text { Plaque } \\
\text { Index }\end{array}$} & \multicolumn{2}{|c|}{$\begin{array}{c}\text { Experimental sites } \\
\text { (Group A) }\end{array}$} & \multicolumn{2}{|c|}{$\begin{array}{c}\text { Control sites } \\
\text { (Group B) }\end{array}$} & \multirow[t]{2}{*}{ P value } \\
\hline & Mean \pm SD & $\begin{array}{l}\% \\
\text { Change } \\
\text { from } \\
\text { baseline }\end{array}$ & Mean \pm SD & $\begin{array}{l}\% \\
\text { Change } \\
\text { from } \\
\text { baseline }\end{array}$ & \\
\hline Baseline & $\begin{array}{l}245.5 \pm 63.071 \\
(\mathrm{~N}=20)\end{array}$ & -- & $\begin{array}{l}289.45 \pm 55.618 \\
(\mathrm{~N}=20)\end{array}$ & -- & $\begin{array}{l}\mathrm{t}=2.3374 \\
\mathrm{p}<0.05^{\star}\end{array}$ \\
\hline $14^{\text {th }}$ day & $\begin{array}{l}18.57 \pm 9.748 \\
(\mathrm{~N}=20)\end{array}$ & $91.10 \%$ & $\begin{array}{l}136 \pm 26.983 \\
(\mathrm{~N}=20)\end{array}$ & $50.00 \%$ & $\begin{array}{l}t=17.8676 ; \\
p<0.0001^{* *}\end{array}$ \\
\hline $\begin{array}{l}\text { Significance } \\
0 \text { day v/s } \\
14 \text { days }\end{array}$ & \multicolumn{2}{|c|}{$\mathrm{t}=13.228 ; \mathrm{p}<0.0001$} & \multicolumn{2}{|c|}{$\mathrm{t}=12.292 ; \mathrm{p}<0.0001$} & -- \\
\hline
\end{tabular}

**Highly significant

*Significant

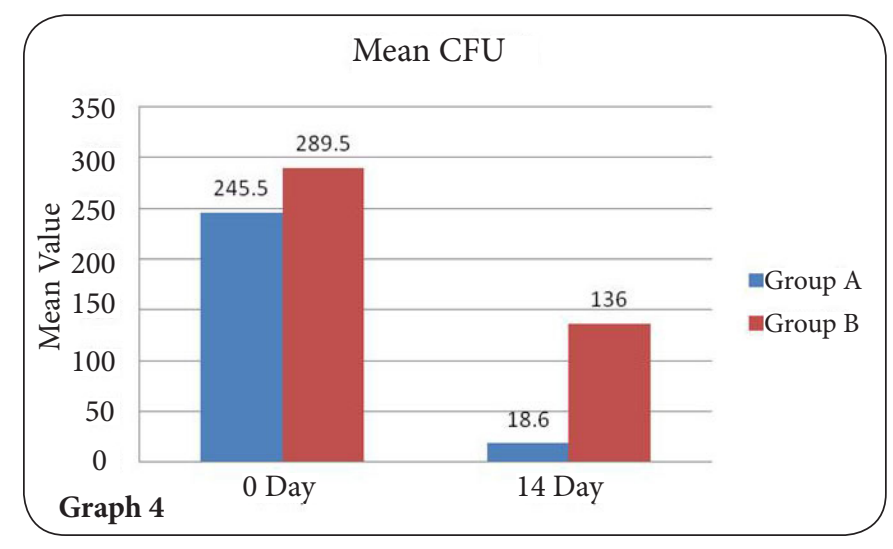


Chandrashekar et al. Oral Biology and Dentistry 2015,

improvement in the clinical parameters as compared to baseline in both the groups; however, the inter-group comparison was not significant. While on comparison of the change in the colony forming units of Aggregatibacter actinomycetemcomitans as obtained from the subgingival plaque samples, significant improvement were seen in the test group.

The prevalence of Aggregatibacter actinomycetemcomitans is nearly $90 \%$ in localized juvenile periodontitis, 30-50\% in severe adult periodontitis, and also encountered frequently in rapidly progressing periodontitis. Factors that promote Aggregatibacter actinomycetemcomitans colonization and persistence in the oral cavity include adhesins, bacteriocins, invasins and antibiotic resistance [11]. Studies have shown that Aggregatibacter actinomycetemcomitans cannot be completely eradicated from the subgingival sites by mechanical therapy alone [12]. Persistence of Aggregatibacter actinomycetemcomitans after treatment has been correlated with its frequency before treatment. Individuals showing evidence of Aggregatibacter actinomycetemcomitans in a multitude of sites appear to be more difficult to treat than patients with few positive sites only. Also, deeper pockets show a greater resistance to eradication of Aggregatibacter actinomycetemcomitans [13]. It has been suggested that a possible explanation for this might be that Aggregatibacter actinomycetemcomitans invades the gingival tissues and therefore are more difficult to eradicate using non-surgical therapy [12].

Various studies have shown that successful reduction of $A g g$ regatibacter actinomycetemcomitans and improvement in clinical results was seen with employment of combination of therapeutic modalities, i.e., mechanical as well as chemotherapeutic [14]. When compared to other commercially available antibiotics for use as local drug delivery agents, tetracycline provides better results in terms of clinical [15] and microbiological status [16]. However, studies on the duration of the maintenance of the improved periodontal status have been contradictory. Aimetti M et al., (2004) reported absence of recolonization of periodontal pocket by periopathogens over a 12 months follow up period after treatment with SRP and tetracycline fibres [17]. While, Man-Ying Wong (1999) reported recolonization by bacteria as early as 3-6 months [18]. It was suggested that the bacteria from the other untreated niches of the oral cavity, such as cheek, tongue mucosa, saliva, or untreated sites may contribute to reinfection of the pockets and explain the insignificant response to local tetracycline therapy [18]. Since the present study was of fourteen days, it is beyond its scope to comment on duration over which the reduction in the level of Aggregatibacter actinomycetemcomitans can be maintained.

Administration of an antibiotic directly into the periodontal pocket provides various advantages. Apart from bypassing first pass metabolism, systemic side effects and maintaining higher concentration at the diseased site, development of resistance to antibiotics, when administered locally, has also not yet been observed for periopathogens.

Aggregatibacter actinomycetemcomitans strains have been found to be most susceptible to amoxicillin/clavulanic acid, tetracycline and metronidazole with $0 \%, 0.8 \%$ and $20.8 \%$ nonsusceptible isolates, respectively [19]. The susceptibility of the different strains of Aggregatibacter actinomycetemcomitans varies according to geographic location also. It was found that $100 \%$ of subgingival Aggregatibacter actinomycetemcomitans isolated from Spanish patients grew on tetracycline-containing agar plates versus $0 \%$ isolated from Dutch patients [20]. The present study definitively concludes that the strain of Aggregatibacter actinomycetemcomitans found in Indian population is susceptible to tetracycline.

\section{Conclusion}

Chemotherapeutic agents act as a useful adjunct to conventional mechanical therapy in patients with refractory periodontitis, in medically compromised patients and for patients where surgical intervention is contraindicated. Since, the susceptibility of $A g$ gregatibacter actinomycetemcomitans to antibiotics decreases with maturation of biofilm, [21] the first requirement of periodontal therapy is to disrupt the established biofilm. As evident from this study, it can be assumed that tetracycline fibre therapy along with scaling and root planing is more effective than scaling and root planing alone. However, further long term studies should be undertaken to obtain more clinical evidence for regular use of this material on clinical parameter for a larger sample.

\section{Limitation of the study}

The present clinical trial was conducted for a short duration of forteen days. Also, the other putatuive periodontal pathogens were not assessed and thus, no conclusions can be drawn on their effect on periodontitis and efficacy of tetracyclline fibres against these bacteria.

\section{Competing interests}

The authors declare that they have no competing interests.

\section{Authors' contributions}

All authors contributed equally to the manuscript.

\section{Acknowledgement}

The study was conducted in Hitkarini Dental College and Hospital, Jabalpur, Madhya Pradesh, India. The authors wish to acknowledge the assistance of Daksh Pathological Laboratories for their assistance with the anaerobic microbiological culture and data collection and interpretation.

\section{Publication history}

Received: 31 October 2014 Revised: 09 January 2015

Accepted: 21 January 2015 Published: 31 January 2015

\section{References}

1. Glossary of periodontal terms. 2001. $4^{\text {th }}$ edition.

2. Haffajee, A. D., Cugini, M. A., Dibart, S., Smith, C., Kent, R. L., Jr. and Socransky, S. S. (1997). Clinical and microbiological features of subjects with adult periodontitis who responded poorly to scaling and root planing. J Clin Periodontol, 24, 767-76.

3. Kornman, K. S. and Robertson, P. B. (1985). Clinical and 
Chandrashekar et al. Oral Biology and Dentistry 2015,

microbiological evaluation of therapy for juvenile periodontitis. $J$ Periodontol, 56, 443-6.

4. Newman, Takei, Klokkevold, Carranza: Clinical Periodontology. 10th edition, 134-186.

5. Drisko, C. H. (2001). Nonsurgical periodontal therapy. Periodontol 2000, 25, 77-88.

6. Golub, L. M., Suomalainen, K. and Sorsa, T. (1992). Host modulation with tetracyclines and their chemically modified analogues. Curr Opin Dent, 2, 80-90.

7. Haffajee, A. D., Socransky, S. S. and Gunsolley, J. C. (2003). Systemic anti-infective periodontal therapy. A systematic review. Ann Periodontol, 8, 115-81.

8. Greenstein, G. (2005). Changing periodontal concepts: treatment considerations. Compend Contin Educ Dent, 26, 81-2, 84-86.

9. Lenox, J. A. and Kopczyk, R. A. (1973). A clinical system for scoring a patient's oral hygiene performance. J Am Dent Assoc, 86, 849-52.

10.Wilkins, T. D. and Chalgren, S. (1976). Antimicrobial Agents. Chemother, 10, 926-8.

11.Paula, M., Fives-Taylor, Diane Hutchins Meyer., Keith, P. Mintz. and Catherine Brissette (2000). Virulence factors of Actinobacillus actinornycetemconzitans. Periodontology, 20, 136-67.

12. Renvert, S., Wikstrom, M., Dahlen, G., Slots, J. and Egelberg, J. (1990). On the inability of root debridement and periodontal surgery to eliminate Actinobacillus actinomycetemcomitans from periodontal pockets. J Clin Periodontol, 17, 351-5.

13. Mombelli, A., Gmur, R., Gobbi, C. and Lang, N. P. (1994). Actinobacillus actinomycetemcomitans in adult periodontitis. II. Characterization of isolated strains and effect of mechanical periodontal treatment. J Periodontol, 65, 827-34.

14.Pavicic, M. J., van Winkelhoff, A. J., Douque, N. H., Steures, R. W. and de Graaff, J. (1994). Microbiological and clinical effects of metronidazole and amoxicillin in Actinobacillus actinomycetemcomitans-associated periodontitis. A 2-year evaluation. J Clin Periodontol, 21, 107-12.

15. Kinane, D. F. and Radvar, M. (1999). A six-month comparison of three periodontal local antimicrobial therapies in persistent periodontal pockets. J Periodontol, 70, 1-7.

16. Goodson, J. M., Tanner, A., McArdle, S., Dix, K. and Watanabe, S. M. (1991). Multicenter evaluation of tetracycline fiber therapy. III. Microbiological response. J Periodontal Res, 26, 440-51.

17. Aimetti, M., Romano, F., Torta, I., Cirillo, D., Caposio, P. and Romagnoli, R. (2004). Debridement and local application of tetracycline-loaded fibres in the management of persistent periodontitis: results after 12 months. J Clin Periodontol, 31, 16672.

18. Wong, M. Y., Lu, C. L., Liu, C. M. and Hou, L. T. (1999). Microbiological response of localized sites with recurrent periodontitis in maintenance patients treated with tetracycline fibers. J Periodontol, 70, 861-8.

19. Kulik, E. M., Lenkeit, K., Chenaux, S. and Meyer, J. (2008). Antimicrobial susceptibility of periodontopathogenic bacteria. $J$ Antimicrob Chemother, 61, 1087-91.

20.van Winkelhoff, A. J., Herrera Gonzales, D., Winkel, E. G., Dellemijn-Kippuw, N., Vandenbroucke-Grauls, C. M. and Sanz, M. (2000). Antimicrobial resistance in the subgingival microflora in patients with adult periodontitis. A comparison between The Netherlands and Spain. J Clin Periodontol, 27, 79-86.

21. Takahashi, N., Ishihara, K., Kato, T. and Okuda, K. (2007). Susceptibility of Actinobacillus actinomycetemcomitans to six antibiotics decreases as biofilm matures. J Antimicrob Chemother, 59, 59-65.

\section{Citation:}

Kataria S, Chandrashekar K.T, Mishra R, Tripathi

V, Galav A and Sthapak U. Effect of tetracycline

HCL (periodontal plus AB) on Aggregatibacter actinomycetemcomitans levels in chronic periodontitis. Oral Biol Dent. 2015; 3:2.

http://dx.doi.org/10.7243/2053-5775-3-2 